\title{
Study on the inhibition of Mild Steel Corrosion by Cationic Surfactant in HCl Medium
}

\author{
Prathibha B.S ${ }^{1}$ P.Kotteeswaran ${ }^{2}$, V. Bheema Raju ${ }^{3}$, \\ ${ }^{1}$ Department of chemistry, BNM Institute of Technology, Bengaluru-70, India \\ ${ }^{2}$ Department of chemistry, Kalasalingam University, Tamil Nadu, India \\ ${ }^{3}$ Department of chemistry, Dr. Ambedkar Institute of Technology, Bengaluru, India
}

\begin{abstract}
The inhibition effect of N,N,N-trimethyldodecylammonium bromide(TDAB) as a cationic surfactant on the corrosion of mild steel in $1 \mathrm{M} \mathrm{HCl}$ has been studied at different temperatures by weight loss, Tafel polarization and Electrochemical impedance spectroscopy. Morphology of the mild steel specimens were examined using scanning electron microscopy and AFM in presence and absence of inhibitor. The results show that TDAB is a good inhibitor, and the inhibition efficiency (IE) increases with the inhibitor concentration as well as increasing the temperature. The adsorption of inhibitor on the mild steel surface obeys the Langmuir adsorption isotherm equation. Polarization curves show that TDAB is a mixed-type inhibitor in hydrochloric acid. Activation parameters and thermodynamic parameters were also discussed. The results obtained from weight loss, polarizations and EIS are in good agreement.
\end{abstract}

Keywords: AFM, Cationic surfactant, , Corrosion inhibition, mild steel, Polarization

\section{Introduction}

Acids are widely used in various technological processes in industry, e.g., in pickling baths, in the extraction and processing oil and gas and in other chemical and petrochemical industries. Also, in the technical cracking of petroleum, acids appear as a result of hydrolysis of salts and may destructive effect on the equipment. Corrosion due to acids are important and expensive problem in the petroleum refining units and it represents a significant portion of loss as a result of lost production, inefficient operation, high maintenance and the cost of corrosion control chemicals. Inhibitors should be effective in low concentrations for economy. The use of inhibitors is the most practical methods for protection against corrosion, especially in acid media[1]. Most of the well known acid inhibitors are organic compounds containing nitrogen, sulphur and oxygen atoms. The influence of organic compounds containing nitrogen, such as amines and heterocyclic compounds, on the corrosion of steel in acidic solutions has been investigated by several workers [2-5].

In previous studies, SDBS [6], Dithizone and thiosemicarbazide [7], Benzyl triethanol ammonium chloride [8], Cetyl trimethyl ammonium bromide, etc have been studied as corrosion inhibitors for steel in acidic medium.The existing data shows that the most organic inhibitors acts by adsorption on the metal surface. Surfactant inhibitors have many advantages, for example, high inhibition efficiency, low price, low toxicity, and easy production $[9,10$,$] . Moreover, the investigation of surfactants adsorbed on metal surface is extremely$ important in electrochemical studies such as corrosion inhibition, adhesion, lubrication and detergency [10]. Nowadays, surfactants are widely used and find a very large number of applications in the petroleum industry. This is attributed to their significant capability to influence the properties of surfaces and interfaces. An important corrosion inhibition tool is the use of surfactant inhibitors, because of very little consideration towards this study. The most important action of inhibition is the adsorption of the surfactant functional group on to the metal surface, adsorption is critical to corrosion inhibition. The concern of these materials arises from their significance in recent civilization.

In the present investigation the corrosion inhibition of mild steel in $1 \mathrm{M} \mathrm{HCl}$ solution in the absence and presence of a surfactant, N,N,N-trimethyldodecylammonium bromide(TDAB) has been studied using weight loss, potentiodynamic polarization and Electrochemical impedance spectroscopy techniques. The effects of temperature and concentration have been studied. The surface morphology of the mild steel surface after exposing to a optimum concentration is also examined using AFM and SEM.

\subsection{Preparation of specimen}

\section{Experimental}

Mild steel specimen with composition (Fe, 98.7; C, 0.223; Mn, 0.505; Si, 0.164; S, 0.05) was used. For the weight loss measurement mild steel specimen $(2 \mathrm{~cm} \times 1 \mathrm{~cm})$ was used and for electrochemical polarization investigation, The cylindrical rod specimen was welded with copper wire for electrical connection and embedded in Teflon holder using epoxy resin with an exposed area $1 \mathrm{~cm}^{2}$. Before each experiment, the electrode 
was first mechanically polished with various grades of emery paper $(0 / 0,2 / 0,3 / 0, \& 4 / 0)$ and then cleaned with methanol and acetone followed by cleaning with double distilled water.

\subsection{Inhibitor and electrolyte}

TDAB is dissolved in $1 \mathrm{M} \mathrm{HCl}$ solution at various concentrations $\left(10^{-2}, 6 \times 10^{-3}, 4 \times 10^{-3}, 2 \times 10^{-3}\right.$ and $10^{-}$ $\left.{ }^{3} \mathrm{M}\right)$ and the solution in the absence of TDAB was taken as blank for comparison. Aggressive solution (1MHCl), was prepared by dilution of reagent grade $34 \% \mathrm{HCl}$ with double distilled water.

\section{3 weight loss studies}

MS samples $(2 \mathrm{~cm} \times 1 \mathrm{~cm})$ were used for weight loss measurement studies at various temperatures (298K-328K) for $3 \mathrm{~h}$ exposure time. The \% IE was calculated by using an equation 1 :

$$
\% I E=\frac{W^{0}-W}{W^{0}} X 100
$$

Where $W^{0}=$ weight loss without inhibitor, $W=$ weight loss with inhibitor

\subsection{Electrochemical experiment}

Electrochemical experiments were performed in a conventional three electrode cell, mild steel welded with copper wire and embedded in Teflon holder using epoxy resin with an exposed area $1 \mathrm{~cm}^{2}$ as Working electrode, a platinum foil of $1 \mathrm{~cm}^{2}$ was used as counter electrode $\&$ the reference electrode was a saturated calomel electrode (SCE) with a Luggin capillary. All potentials are measured with respect to the SCE. Measurements were performed using $\mathrm{CHI}$ 660C model Electrochemical workstation. Potentiodynamic polarization curves were obtained by scanning the potential range from $-200 \mathrm{mv}+\mathrm{E}_{\text {corr }}$ to $+200 \mathrm{mv}+\mathrm{E}_{\text {corr }}$ at a scan rate of $10 \mathrm{mv} / \mathrm{s}$ after $1 \mathrm{~h}$ immersion time in $1 \mathrm{M} \mathrm{HCl}$ and $1 \mathrm{M} \mathrm{HCl}+$ inhibitor solutions. Potentiodynamic polarization curves were also obtained at different temperatures to calculate the activation energy of the inhibitor adsorption to mild steel surface. The \%IE was calculated from the measured $\mathrm{I}_{\text {corr }}$ values using the equation 2:

$$
\% I E=\frac{I_{\text {corr }}^{0}-I}{I_{\text {corr }}^{0}} \times 100
$$

Where, $I_{\text {corr }}^{0} \& I$ are the corrosion current densities in absence and presence of inhibitor respectively Electrochemical impedance measurements were carried out at open - circuit potential over a frequency range of $0.01 \mathrm{~Hz}-100 \mathrm{KHz}$. The sinusoidal potential perturbation was $10 \mathrm{mv}$ in amplitude. Electrochemical data were obtained after $1 \mathrm{~h}$ of immersion with the working electrode at the rest potential \& all tests have been performed in non-deaerated solutions under stirred conditions. The \%IE was calculated from the Charge transfer resistance $\left(\mathrm{R}_{\mathrm{ct}}\right)$ values using the following equation 3 :

$$
\% I E=\frac{R_{c t}-R_{c t}^{0}}{R_{c t}} \times 100
$$

Where $R_{c t} \& R_{c t}^{0}$ are the charge transfer resistance in presence and absence of inhibitor respectively

\subsection{Surface analysis by SEM and AFM}

The morphology of the sample surface before and after being treated with optimal concentration of inhibitor was examined by SEM and AFM.

\section{Results and discussion}

\section{1 weight loss}

Fig. 1 shows the plot of \%IE versus inhibitor concentration, it is evident that the \%IE and corrosion rate are concentration dependent. Table 1 shows the variation of inhibition efficiency obtained from weight loss measurements at different concentration of TDAB. The inhibition efficiency increases with increase in inhibitor concentration; the maximum inhibition efficiency was obtained at $10^{-2} \mathrm{M}$. The influence of temperature on inhibition efficiency is shown in Fig. 2. The inhibition efficiency increases by increasing the temperature from 298K-328K. The increase in efficiency with temperature as shown in Table 1 may be attributed to the stability of adsorbed film of inhibitor molecules on the metal surface, which are adsorbed strongly even at higher temperature.

\subsection{Potentiodynamic polarization}

The Tafel polarization behaviors of mild steel in $1 \mathrm{M} \mathrm{HCl}$ with the addition of various concentrations of TDAB at different temperatures are shown in Fig. 3. The Corrosion kinetic parameters derived from these curves are presented in Table 2. From the Table 2 it is clear that the corrosion current $\left(\mathrm{I}_{\text {corr }}\right)$, values of mild steel decreases with the addition of TDAB in $1 \mathrm{M} \mathrm{HCl}$. Further the $\mathrm{E}_{\text {corr }}$ value shifts to a positive direction but no significant change is observed, which suggests a mixed type of inhibition effect of TDAB. 


\subsection{Electrochemical impedance spectroscopy}

The experimental results obtained from EIS measurements for the corrosion of mild steel in the presence and absence of inhibitor at $25^{\circ} \mathrm{C}$ are summarized in Table 3 . The impedance spectra for mild steel in $1 \mathrm{M} \mathrm{HCl}$ with and without the various concentrations of TDAB at $25^{\circ} \mathrm{C}$ are presented as Nyquist plot shown in Fig. 4. It can be concluded from the Fig. 4 the impedance response of mild steel significantly changed after the addition of TDAB in the corrosive solution. Fig. $5 \mathrm{a}$ and $\mathrm{b}$ represents the equivalent circuit design used to fit the experimental data of EIS for hydrochloric acid in the absence and presence of inhibitor. The circuit elements for the obtained data include a solution resistance $\left(\mathrm{R}_{\mathrm{s}}\right)$, a constant phase element $(\mathrm{CPE})_{\text {ad }}$ corresponds to adsorption resistance $\left(R_{a}\right)$, charge transfer resistance $\left(R_{c t}\right)$, adsorption resistance $\left(R_{a}\right)$. The proposed models successfully described the phenomenon occurring in the studied system. Table 3 indicates that the charge transfer resistance (Rct), increased with increasing TDAB concentration. The decrease in $\mathrm{C}_{\mathrm{dl}}$, which resulted from decrease in local dielectric constant and or an increase in the thickness of the electrical double layer, suggests that TDAB acted via adsorption at the metal/ solution interface [11]. The values of $Y_{a}$ and $Y_{d l}\left(Y_{a} \& Y_{d l}\right.$ can be regarded to be approximation to the values of the adsorption capacitance and double layer capacitance respectively) has decreased trend for the adsorption of the inhibitor on the metal surface, suggesting the inhibitor molecules displace the water molecules and other ions originally adsorbed on the metal surface. The values of $\mathrm{n}_{\mathrm{a}}$ associated with $(\mathrm{CPE})_{\mathrm{a}}$ are found to be in the 0.96-1 interval revealing that adsorbed film are relatively homogeneous. On the other hand, the different values of $n_{a}$ is due to a modification of the chemical composition of the adsorbed film in combination with their thickness as suggested by the $R_{a}$ values. The values of $n_{d l}$ related to $(C P E)_{d l}$ are found in the 0.60-0.77 interval indicating the electrode surface are partially heterogeneous.

\subsection{Adsoprtion isotherms and thermodynamic parameters}

Adsorption of the inhibitor molecule depends mainly on the charge and the nature of metal surface, electronic characteristics of metal surface, adsorption of solvent and other ionic species, on the electrochemical potential at solution interface. The adsorption of isotherm study describes the adsorptive behavior of inhibitor in order to know the adsorption mechanism of inhibitor to the metal surface. The most frequently used adsorption isotherms are Langmuir, Temkin, Frumkin and Freundlich isotherms. The Langmuir adsorption isotherm was found to provide the best description of the adsorption behavior (Fig.6). This suggest that the Langmuir adsorption isotherm provides the best description for the adsorption of TDAB on mild steel surface.

The Langmuir adsorption isotherm is given by the following equation

$$
\frac{C}{\theta}=\frac{1}{K}+C
$$

Where $\mathrm{C}$ is the inhibitor concentration and $\mathrm{K}$ is equilibrium constant of adsorption, which is related to standard free energy of adsorption $\Delta \mathrm{G}^{0}$ ads by:

$$
K=\frac{1}{55.55} \exp \left(\frac{-\Delta G_{a d s}^{0}}{R T}\right)
$$

$\Delta \mathrm{G}_{\text {ads }}^{0}$ is obtained at a given temperature. $\mathrm{K}$ is obtained from the intercept of a plot of $\mathrm{C} / \square$ as a function of $\mathrm{C}$. As seen from the Fig. 6, plot of $\mathrm{C} / \square$ as a function of $\mathrm{C}$ yields a straight line with regression coefficient higher than 0.99 , showing that the adsorption of the inhibitor is fitted to Langmuir adsorption isotherm.

The data reported in the Table 4 reveals that, the adsorptive equilibrium constant $(\mathrm{K})$ increases with increasing the temperature indicating that it is strongly adsorbed even at high temperature. These results suggest that, the inhibition of mild steel is a adsorptive process.

Thermodynamic parameters play an important role in understanding the inhibition mechanism. The enthalpy of adsorption and entropy of adsorption are calculated from the following equations

$$
\log \left(\frac{\theta}{1-\theta}\right)=\log A+\log C_{\text {inh }}-\frac{Q_{\text {ads }}}{2.303 R T}
$$

Where A is a constant, and $Q_{a d s}$ is the heat of adsorption equal to enthalpy of adsorption Enthalpy of adsorption $\left(\Delta H_{a d s}^{0}\right)$ is obtained from the slope of a plot of $\log \left(\frac{\theta}{1-\theta}\right)$ vs $1 /$ T at various concentrations.

The entropy of activation $\left(\Delta S_{a d s}^{0}\right)$ is obtained from the equation :

$$
\Delta \mathrm{G}_{\text {ads }}^{0}=\Delta \mathrm{H}_{\text {ads }}^{0}-\mathrm{T} \Delta \mathrm{S}_{\text {ads }}^{0}
$$

Fig. 7 indicates that there is a good linear relationship between $\log \left(\frac{\theta}{1-\theta}\right)$ and $1 / \mathrm{T}$. The negative sign of $\Delta G_{a d s}^{0}$ Indicates that the inhibitor is spontaneously adsorbed on the metal surface [12]. In the present study, the $\Delta G_{a d s}^{0}$ values obtained ranges from -28.0 to $-36.1 \mathrm{~kJ} / \mathrm{mol}$, which are lower than $-40 \mathrm{~kJ} / \mathrm{mol}$ but higher than -20 $\mathrm{kJ} / \mathrm{mol}$. This indicates that the adsorption is neither typical physisorption nor typical chemisorptions but it is 
complex mixed type. That is the adsorption inhibitor molecules on the mild steel surface in the present study involves both physisorption and chemisorptions (Comprehensive adsorption). As for the value of $\Delta H_{a d s}^{0}$ in Table 4, the sign of $\Delta H_{a d s}^{0}$ is positive indicates the endothermic nature of steel dissolution process. The positive sign of $\Delta S_{a d s}^{0}$ which indicates that an increase in disordering takes place in going from reactants to metaladsorbed species reaction complex.

\subsection{Kinetic parameters}

The kinetic parameters for the corrosion process were calculated from Arrhenius equation and the transition state equation:

$$
i_{\text {corr }}=\operatorname{Aexp} \frac{-E_{a}}{R T}
$$

Where $i_{\text {corr }}$ is the corrosion current density, A is the Arrhenius constant, $\mathrm{E}_{\mathrm{a}}$ is the activation energy and $\mathrm{R}$ is the universal gas constant.

$$
i_{\text {corr }}=\frac{R T}{N h} \exp \left(\frac{\Delta S^{\#}}{R}\right) \exp \left(\frac{\Delta H^{\#}}{R T}\right)
$$

Where $\mathrm{N}$ is Avogadro's constant, $\mathrm{h}$ is planck's constant, $\Delta S^{\neq}$is the change in entropy of activation and $\Delta H^{\neq}$is the change in enthalpy of activation.

$\mathrm{E}_{\mathrm{a}}$ is obtained from the slope of a plot of $\ln \left(i_{\text {corr }}\right.$ ) vs $1 / \mathrm{T}$ (Fig.8), $\Delta S^{\neq}$is obtained from the intercept of a plot of $\log \left(\frac{i_{c o r r}}{T}\right)$ vs $1 / \mathrm{T}$ and $\Delta H^{\neq}$is obtained from the slope of a plot of $\log \left(\frac{\text { icorr }}{T}\right)$ vs $1 / \mathrm{T}$ (Fig. 9).

The kinetic parameters calculated are given in Table 5. It is clear from that Table 5 that the $\mathrm{E}_{\mathrm{a}}$ decreased with increasing concentration of studied inhibitor. Also it is clear that $E_{a}$ values in the presence of inhibitor are lower than that in the absence of inhibitor indicating that the inhibition efficiency increases with increases with temperature. The positive sign of enthalpy of activation reflect the endothermic nature of steel dissolution process meaning that dissolution of steel is difficult. It is clear from the Table 5 that the entropy of activation is large and negative imply that the activated complex in the rate determining step represents an association rather than dissociation step, meaning that a decrease in disordering take place on going from reactant to the activated complex $[13,14]$.

\subsection{SCANNING ELECTRON MICROSCOPY (SEM) and AFM}

The SEM micrographs of the corroded mild steel in $1 \mathrm{M} \mathrm{HCl}$ in the absence and presence of inhibitor are shown in Fig.10 (a - b). In Figure 10a of bare mild steel electrode surface, defects and notches were observed, while a layer of closely packed film was obtained in Figure 10b, and the surface was free from pits and it was smooth. It can be concluded from Figure 10a-b that corrosion does not occur in presence of inhibitor and hence corrosion was inhibited strongly when the inhibitor was present in the solution, then scanning electron microscopy (SEM) observation, confirmed the existence of an absorbed protective film on the mild steel surface.

AFM is a powerful technique to investigate the surface morphology at nano to micro-scale and has become a new choice to study the influence of inhibitor on the generation and the progress of the corrosion at the metal/solution interface. The three dimentional AFM images of the MS surface exposed to $1 \mathrm{M} \mathrm{HCl}$ with and without $10^{-2} \mathrm{M}$ TDAB for $3 \mathrm{~h}$ are shown in the Fig. 11 (a,b and c). it is clearly evident that, the surface is more uniform(Fig.11c) than the surface (Fig.b)in the absence of inhibitor.

\subsection{Conclusion}

The inhibition efficiency obtained by the TDAB is very good at all temperatures. This acts as a surfactant which is widely used as surface acting agents, antimicrobials, in detergents, etc. Moreover surfactants are less toxic, easily available, less cost etc. The future work is to investigate the synergetic effect of Surfactants and plant extracts. Surfactant acts has good biocide activity.

\section{Acknowledgement:}

I thank Roop Singh, general manager, SINSIL International, Bangalore for extending the electrochemical characterization facility.

\section{References}

[1]. Tadros A.B., Abd-el-Nabey B.A, Inhibition of the acid corrosion of steel 4-amino-3-hydrazino-5-thio-1,2,4-triazoles, J. Electroanal. Chem. 246, 1988, 433 .

[2]. Stoyanova A.E., E.I. Sokolova E.I.. Raicheva S.N., The inhibition of mild steel corrosion in $1 \mathrm{M} \mathrm{HCl}$ in the presence of linear and cyclic thiocarbamides- Effect of concenatrtion and temperature of the corrosion medium on their protective action, Corros. Sci. 39, $1997,1595$.

[3]. Alshkel A.G., Hefny M.M., Ismail A.R., Corrosion prevention control, 155, 1987.

[4]. Omar A.M.A., Abdel-Khalek N.A., J. Chem. Engg. 43, 1998, 117

[5]. El-Etre A.Y., Abdallah M., Bull. Of Electrochem. 10, 1994, 471. 
[6]. H. Luo, Y.C. Guan, K.N. Han, Inhibition of mild steel corrosion by sodium dodecy benzene sulphonate and sodium oleate in acidic solutions, Corrosion 54 (8), 1998, 619.

[7]. A. Singh, R.S. Chaudhary, Dithizone and thiosemicarbazide as inhibitors of corrosion of type 304 stainless steel in 1.0M sulphuric acid solution, Br. Corros. J. 31 (4), 1996, 300.

[8]. M.M. Osman, A.M. Omar, A.M. Al-Sabagh,Corrosion inhibition of benzyl triethanol ammonium chloride and its ethoxylate on steel sulphuric acid solution, Mat. Chem. Phys. 50, 1997, 271.

[9]. A. Kumar, E-Journal of chemistry, 5, 2008, 275.

[10]. M. El-Azhar, B. Mernari, M. Traisnel, F. Bentiss, M. Lagrenee, Corrosion inhibition of mild steel by the new class of inhibitors [2,5-bis(n-pyridyl)-1,3,4- thiadiazoles] in acidic media, Corros. Sci. 43 (12), 2001, 2227.

[11]. K. Babic-Samardzija, K.F. Khaled, N. Hackerman, Heterocyclic amines and derivatives as corrosion inhibitors for iron in perchloric acid, Anti Corros. Method and Mater. 52, 2005, 11-21

[12]. Avci G “Corrosion inhibition of indole-3-acetic acid on mild steel in 0.5M HCl”, Colloids Surf., 317, 2008, 730-736

[13]. Marsh J. Advanced organic chemistry, Wiley Eastern $3^{\text {rd }}$ edition, 1988.

[14]. Bentiss F. Lebrini M. and Lagrenee M., Thermodynamic characterization of metal dissolution and inhibitor adsorption process in mild steel/2,5-bis(n-thienyl)1,3,4-thiadiazoles/hydrochloric acid system, Corros. Sci. 47, 2005, 2915.

Table 1.

Inhibition efficiency of various concentrations of TBAB for the corrosion of mild steel in $0.5 \mathrm{MH}_{2} \mathrm{SO}_{4}$ by weight loss method at different temperatures (298K-328K).

\begin{tabular}{|c|c|c|c|c|c|c|c|c|}
\hline & \multicolumn{8}{|c|}{ Temperature } \\
\hline & & 298 & & 308 & & 318 & & 328 \\
\hline $\begin{array}{l}\text { Inhibitor } \\
\text { concentration } \\
\text { (M) }\end{array}$ & $\% \mathrm{IE}$ & $\begin{array}{l}\text { Corrosion } \\
\text { rate }(\mathrm{mm} / \mathrm{y})\end{array}$ & $\% \mathrm{IE}$ & $\begin{array}{l}\text { Corrosion } \\
\operatorname{rate}(\mathrm{mm} / \mathrm{y})\end{array}$ & $\% \mathrm{IE}$ & $\begin{array}{l}\text { Corrosion } \\
\text { rate }(\mathrm{mm} / \mathrm{y})\end{array}$ & $\% \mathrm{IE}$ & $\begin{array}{l}\text { Corrosion } \\
\text { rate }(\mathrm{mm} / \mathrm{y})\end{array}$ \\
\hline Blank & & 36.44 & & 66.4 & & 153.6 & & 278.0 \\
\hline $1 \times 10^{-3}$ & 54.8 & 18.22 & 70.4 & 19.71 & 73.5 & 40.73 & 80.2 & 55.05 \\
\hline $2 \times 10^{-3}$ & 60.4 & 14.32 & 75.8 & 15.99 & 80.2 & 30.32 & 84.3 & 43.71 \\
\hline $4 \times 10^{-3}$ & 65.3 & 12.65 & 80.2 & 13.20 & 82.1 & 27.34 & 86.1 & 38.68 \\
\hline $6 \times 10^{-3}$ & 72.6 & 10.04 & 85.5 & 9.67 & 86.3 & 21.0 & 88.5 & 31.99 \\
\hline $1 \times 10^{-2}$ & 80.4 & 7.06 & 89.7 & 6.88 & 90.2 & 15.06 & 91.3 & 24.17 \\
\hline
\end{tabular}

Table 2.

Electrochemical polarization parameters for $\mathrm{MS}$ in $1 \mathrm{MHCl}$ containing different concentration of TDAB at different temperatures.

\begin{tabular}{|c|c|c|c|c|c|}
\hline Concentration(M) & $\begin{array}{c}\mathbf{E}_{\text {corr }} \\
(\mathbf{m V})\end{array}$ & $\begin{array}{c}\mathbf{i}_{\text {corr }} \\
\left(\square \mathbf{A} / \mathbf{c m}^{2}\right)\end{array}$ & $\begin{array}{c}\mathbf{b}_{\mathbf{a}} \\
(\mathbf{m v} / \mathbf{d e c a d e})\end{array}$ & $\begin{array}{c}\mathbf{b}_{\mathbf{c}} \\
(\mathbf{m v} / \mathbf{d e c a d e})\end{array}$ & $\mathbf{I E}_{\mathbf{1}}(\boldsymbol{\%})$ \\
\hline $\mathbf{2 9 8 K}$ & & & & & \\
\hline $\mathrm{HCl}$ & -502.1 & 2640 & 151.7 & 130.1 & \\
\hline $10^{-3}$ & -464.9 & 900.1 & 140.2 & 182.5 & 65.9 \\
\hline $2 \times 10^{-3}$ & -471.0 & 833.4 & 135.6 & 170.0 & 68.4 \\
\hline $4 \times 10^{-3}$ & -471.3 & 723.5 & 126.6 & 154.8 & 72.6 \\
\hline $6 \times 10^{-3}$ & -466.8 & 492.6 & 119.1 & 126.2 & 81.3 \\
\hline $10^{-2}$ & -464.1 & 384.7 & 115.6 & 115.2 & 85.4 \\
\hline $\mathbf{3 0 8 K}$ & & & & & \\
\hline $\mathrm{HCl}$ & -501.8 & 6354 & 178.8 & 158.7 & \\
\hline $10^{-3}$ & -475.3 & 1120 & 145.8 & 122.2 & 82.3 \\
\hline $2 \times 10^{-3}$ & -491.6 & 1042 & 155.8 & 122.7 & 83.6 \\
\hline $4 \times 10^{-3}$ & -474.8 & 919.7 & 143.0 & 119.4 & 85.5 \\
\hline $6 \times 10^{-3}$ & -447.6 & 675.2 & 136.3 & 112.8 & 89.4 \\
\hline $10^{-2}$ & -472.0 & 558.7 & 127.8 & 113.8 & 91.2 \\
\hline $318 K$ & & & & & \\
\hline $\mathrm{HCl}_{10}^{-3}$ & -500.5 & 14130 & 200.9 & 189.4 & \\
\hline $2 \times 10^{-3}$ & -483.5 & 1955 & 156.8 & 132.9 & 86.2 \\
\hline $4 \times 10^{-3}$ & -481.3 & 1903 & 156.5 & 130.3 & 86.5 \\
\hline $6 \times 10^{-3}$ & -482.2 & 1642 & 154.8 & 129.5 & 88.4 \\
\hline & & 1700 & 158.2 & 132.8 & \\
\hline
\end{tabular}


Study On The Inhibition Of Mild Steel Corrosion By Cationic Surfactant In Hcl Medium

\begin{tabular}{|c|c|c|c|c|c|}
\hline $10^{-2}$ & -480.7 & 1065 & 153.0 & 127.0 & 92.5 \\
\hline $\mathbf{3 2 8 K}$ & & & & & \\
\hline $\mathrm{HCl}$ & -494.8 & 26620 & 201.7 & 206.3 & \\
\hline $10^{-3}$ & -463.9 & 3287 & 172.3 & 141.3 & 87.6 \\
\hline $2 \times 10^{-3}$ & -495.1 & 2696 & 161.9 & 141.1 & 89.9 \\
\hline $4 \times 10^{-3}$ & -488.1 & 2560 & 163.2 & 142.5 & 90.4 \\
\hline $6 \times 10^{-3}$ & -488.4 & 2444 & 159.4 & 136.9 & 90.8 \\
\hline $10^{-2}$ & -487.2 & 1625 & 143.8 & 129.8 & 93.9 \\
\hline
\end{tabular}

Table 3

Impedance parameters of mild steel in $1 \mathrm{M} \mathrm{HCl}$ absence and presence of different concentration of TDAB at

\begin{tabular}{|c|c|c|c|c|c|c|c|c|c|}
\hline $\begin{array}{l}\text { Concentr } \\
\operatorname{ation}(M)\end{array}$ & 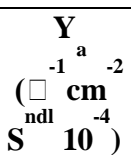 & $\mathbf{n}_{\mathbf{a}}$ & $\begin{array}{l}\mathbf{R}_{\mathrm{a}} \\
(\square)\end{array}$ & $\mathrm{C}_{\mathrm{a}}\left(\square \mathrm{F} / \mathrm{cm}^{2}\right)$ & 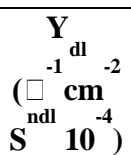 & $\mathbf{n}_{\mathrm{dl}}$ & $\begin{array}{l}\mathbf{R}_{\mathrm{ct}} \\
(\square)\end{array}$ & $\begin{array}{c}\mathrm{C}_{\mathrm{dl}}{ }^{2} \\
\left(\square \mathrm{F} / \mathrm{cm}^{2}\right. \\
)\end{array}$ & $\begin{array}{l}\mathrm{IE} \\
(\%)\end{array}$ \\
\hline Blank & & & & & 18.20 & 0.8561 & 9.979 & 927.8 & \\
\hline $10^{-3}$ & 34.37 & 0.9678 & 0.4726 & 2775.6 & 91.28 & 0.6285 & 25.12 & 3822.2 & 60.3 \\
\hline $2 \times 10^{-3}$ & 2.941 & 0.9700 & 0.6282 & 225.4 & 83.9 & 0.6285 & 26.39 & 3441.2 & 62.2 \\
\hline $4 \times 10^{-3}$ & 1.991 & 1 & 0.7677 & 199.1 & 76.2 & 0.6000 & 38.59 & 3369.6 & 74.1 \\
\hline $6 \times 10^{-3}$ & 0.8637 & 1 & 6.231 & 86.37 & 39.1 & 0.7702 & 43.25 & 2298.6 & 76.9 \\
\hline $10^{-2}$ & 0.8545 & 1 & 18.57 & 85.45 & 12.95 & 0.6562 & 98.97 & 441.4 & 89.9 \\
\hline
\end{tabular}

Table 4

Data obtained from the Langmuir adsorption isotherm for mild steel in $1 \mathrm{M} \mathrm{HCl}$ at the temperature range of $298 \mathrm{~K}-328 \mathrm{~K}$

\begin{tabular}{|l|c|c|c|c|c|c|}
\hline Temperature $(\mathrm{K})$ & $\mathrm{R}$ & Slope & $\mathrm{K}_{\text {ads }}$ & $\Delta \mathrm{G}^{\mathrm{o}}{ }_{\mathrm{ads}}\left(\mathrm{kJmol}^{-1}\right)$ & $\Delta \mathrm{H}^{\mathrm{o}}{ }_{\text {ads }}\left(\mathrm{kJmol}^{-1}\right)$ & $\Delta \mathrm{S}^{\mathrm{o}}{ }_{\text {ads }}\left(\mathrm{Jmol}^{-1} \mathrm{~K}^{-1}\right)$ \\
\hline 298 & 0.9982 & 1.1167 & 1490.1 & -28.0 & 30.4 & 196.3 \\
\hline 308 & 0.9974 & 1.0781 & 4336.0 & -31.7 & 30.4 & 201.7 \\
\hline 318 & 0.9995 & 1.0737 & 5298.0 & -33.3 & 30.4 & 200.4 \\
\hline 328 & 0.9997 & 1.0630 & 10019.6 & -36.1 & 30.4 & 202.7 \\
\hline
\end{tabular}

Table 5

Corrosion kinetic parameters for mild steel in $1 \mathrm{M} \mathrm{HCl}$ in the absence and presence of different concentrations of TDAB.

\begin{tabular}{|l|c|c|c|}
\hline Concentration $(\mathrm{M})$ & $\mathrm{E}_{\mathrm{a}}(\mathrm{kJ} / \mathrm{mol})$ & $\Delta \mathrm{H}^{\ddagger}(\mathrm{kJ} / \mathrm{mol})$ & $\Delta \mathrm{S}^{\ddagger}\left(\mathrm{J} / \mathrm{mol} / \mathrm{K}^{-1}\right)$ \\
\hline Blank & 64.28 & 53.35 & -115.89 \\
\hline $10^{-3}$ & 36.9 & 28.9 & -207.5 \\
\hline $2 \times 10^{-3}$ & 34.3 & 26.8 & -214.9 \\
\hline $4 \times 10^{-3}$ & 36.6 & 28.7 & -182.1 \\
\hline $6 \times 10^{-3}$ & 47.3 & 37.9 & -209.6 \\
\hline $10^{-2}$ & 41.3 & 32.9 & -200.5 \\
\hline
\end{tabular}

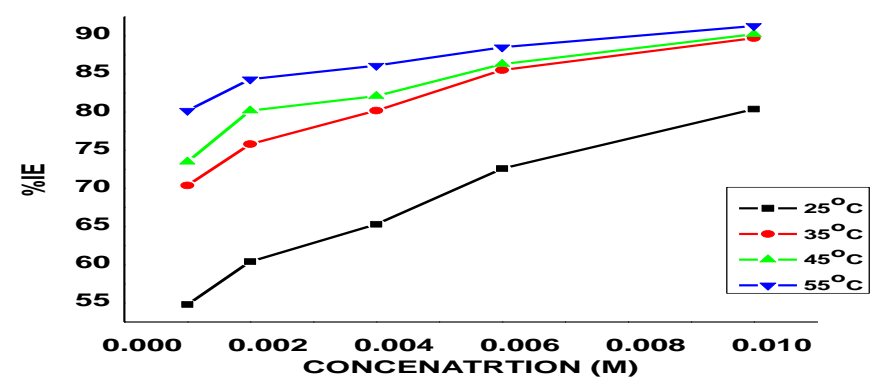

Fig. 1 Variation of \%IE with concentration obtained from weight loss method. 


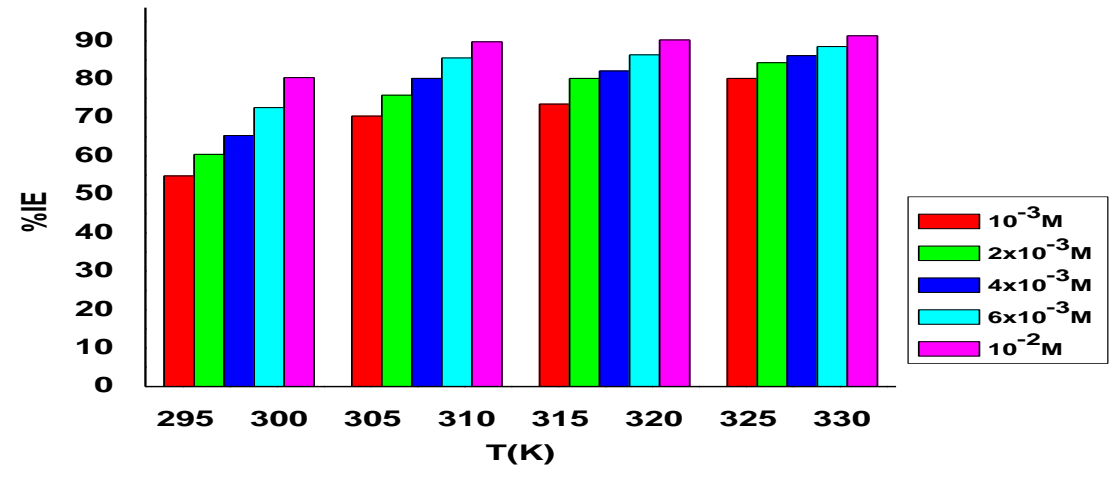

Fig. 2 Variation of \%IE with temperature for different concentration of TBAB
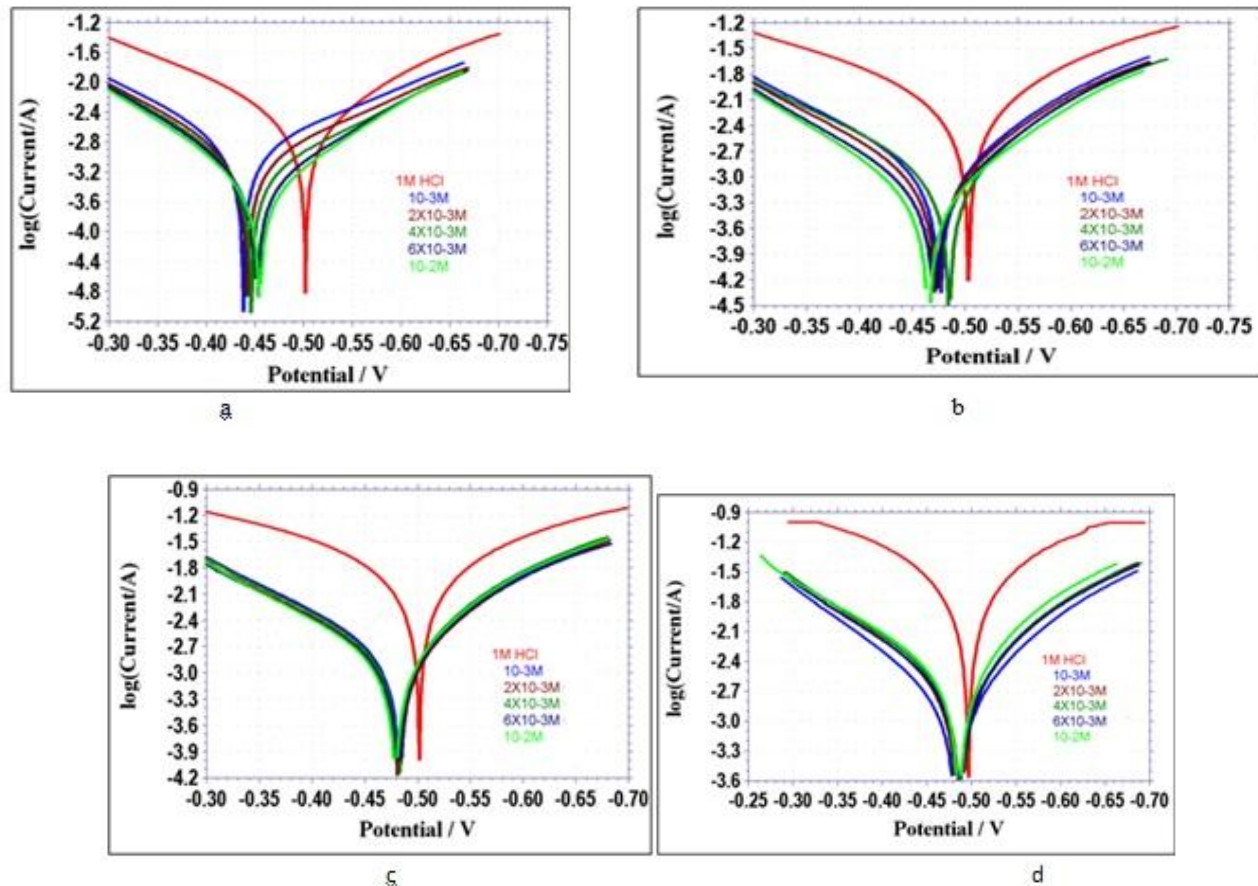

Fig. 3Typical Tafel plots of MS in $0.5 \mathrm{MH}_{2} \mathrm{SO}_{4}$ in presence and absence of different concentration of TDAB at a ) $25^{\circ} \mathrm{C}$ b) $35^{\circ} \mathrm{C}$ c) $45^{\circ} \mathrm{C} \&$ d) $55^{\circ} \mathrm{C}$

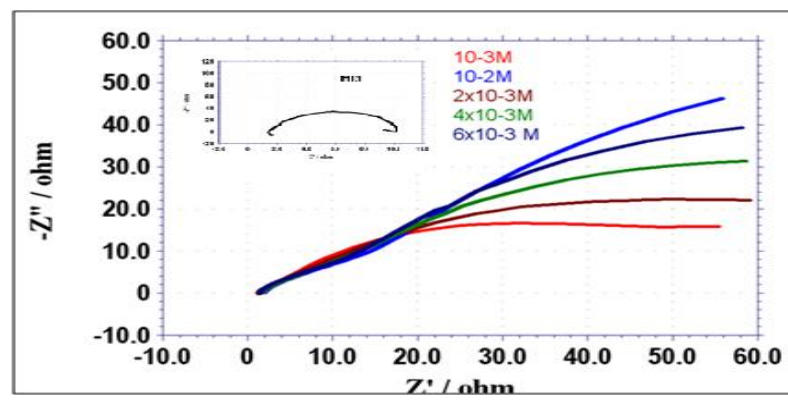

Fig. 4 Nyquist Plots of mild steel in $1 \mathrm{M} \mathrm{HCl}$ absence and presence of TDAB 


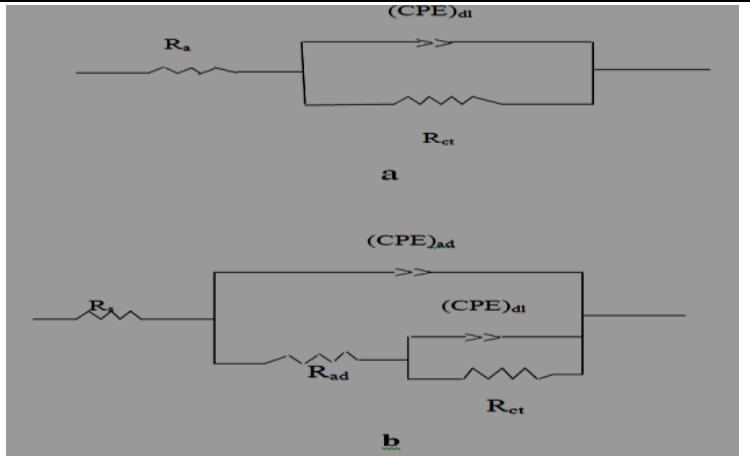

Fig. 5 The equivalent circuit model used to fit the impedance data for mild steel in the absence (a) and in the presence (b) of TDAB

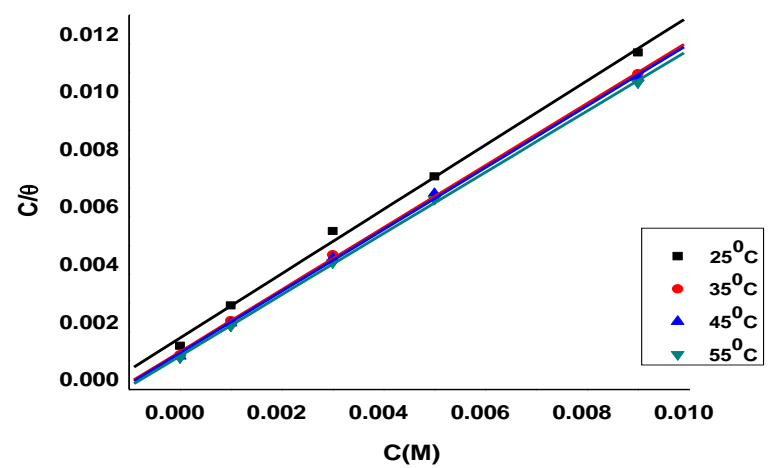

Fig. 6 Langmuir adsorption isotherms of TDAB at different temperatures

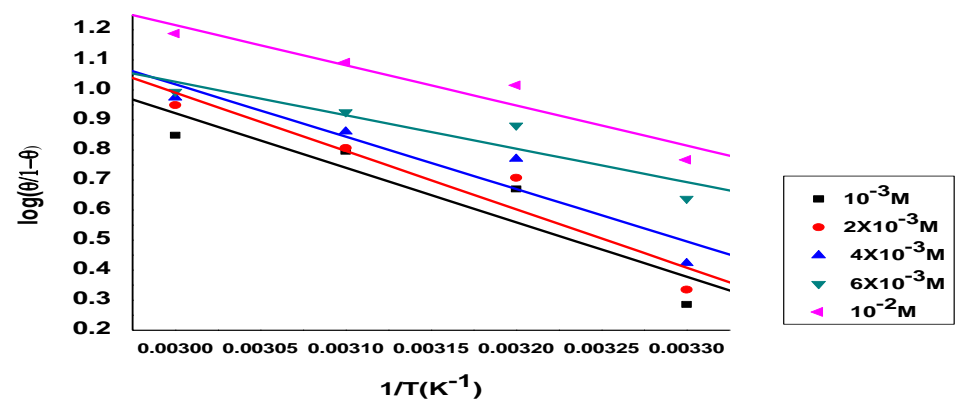

Fig. 7 Variation of $\log \left(\frac{\theta}{1-\theta}\right)$ vs $1 / \mathrm{T}$

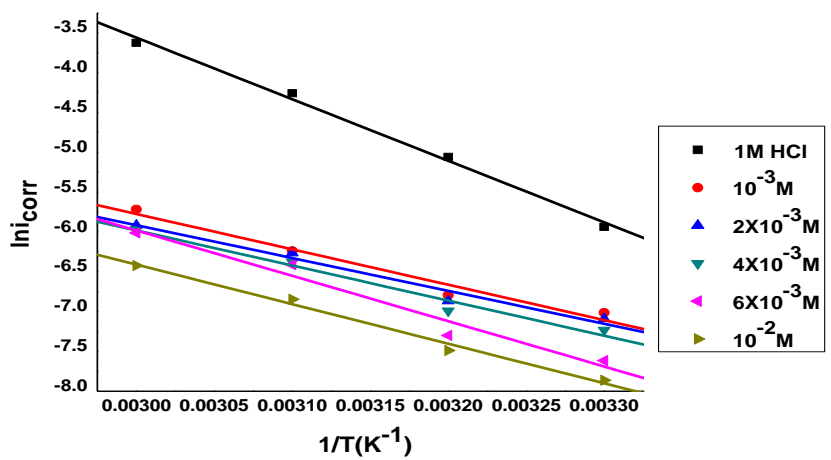

Fig. 8 Arrhenius plots for mild steel in $1 \mathrm{M} \mathrm{HCl}$ without and with various concentration of TDAB 


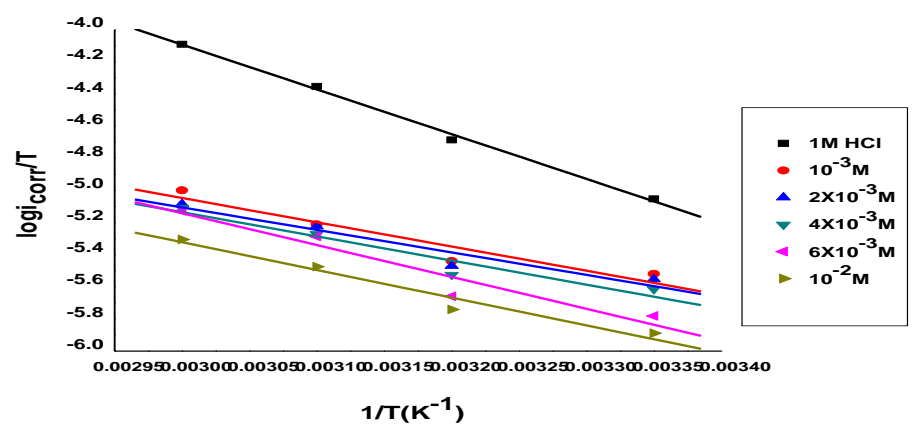

Fig. 9 Transition state plots for mild steel in $1 \mathrm{M} \mathrm{HCl}$ without and with various concentration of TDAB

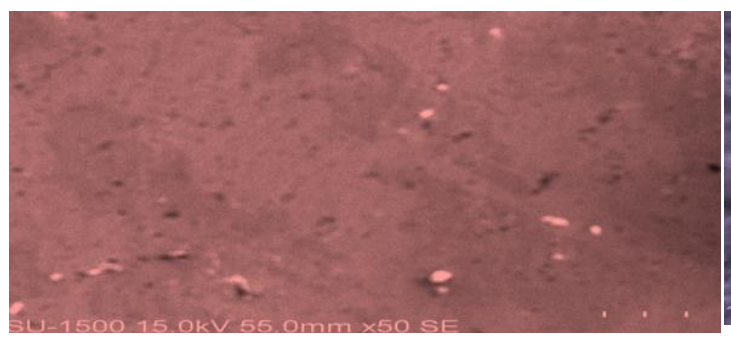

a

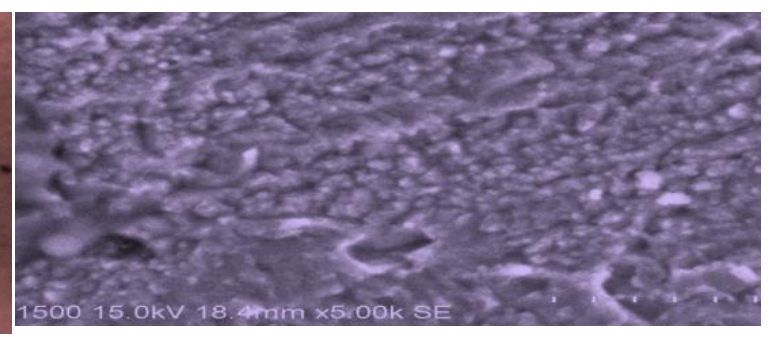

b

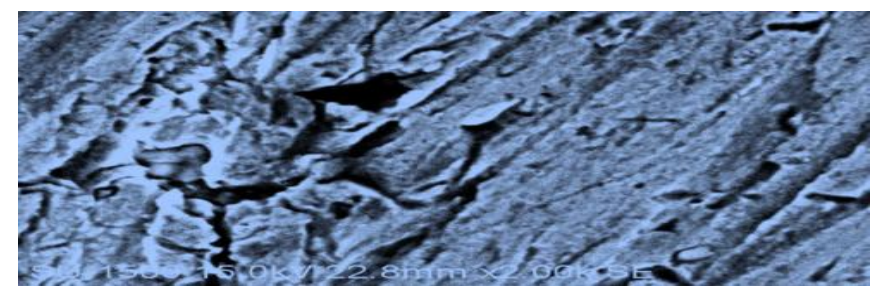

$\mathrm{c}$

Fig. 10 Surface Characterization by SEM for mild steel in $1 \mathrm{M} \mathrm{HCl}$ a) Polished surface $\mathrm{b}$ ) in the absence of inhibitor c) in the presence of TDAB
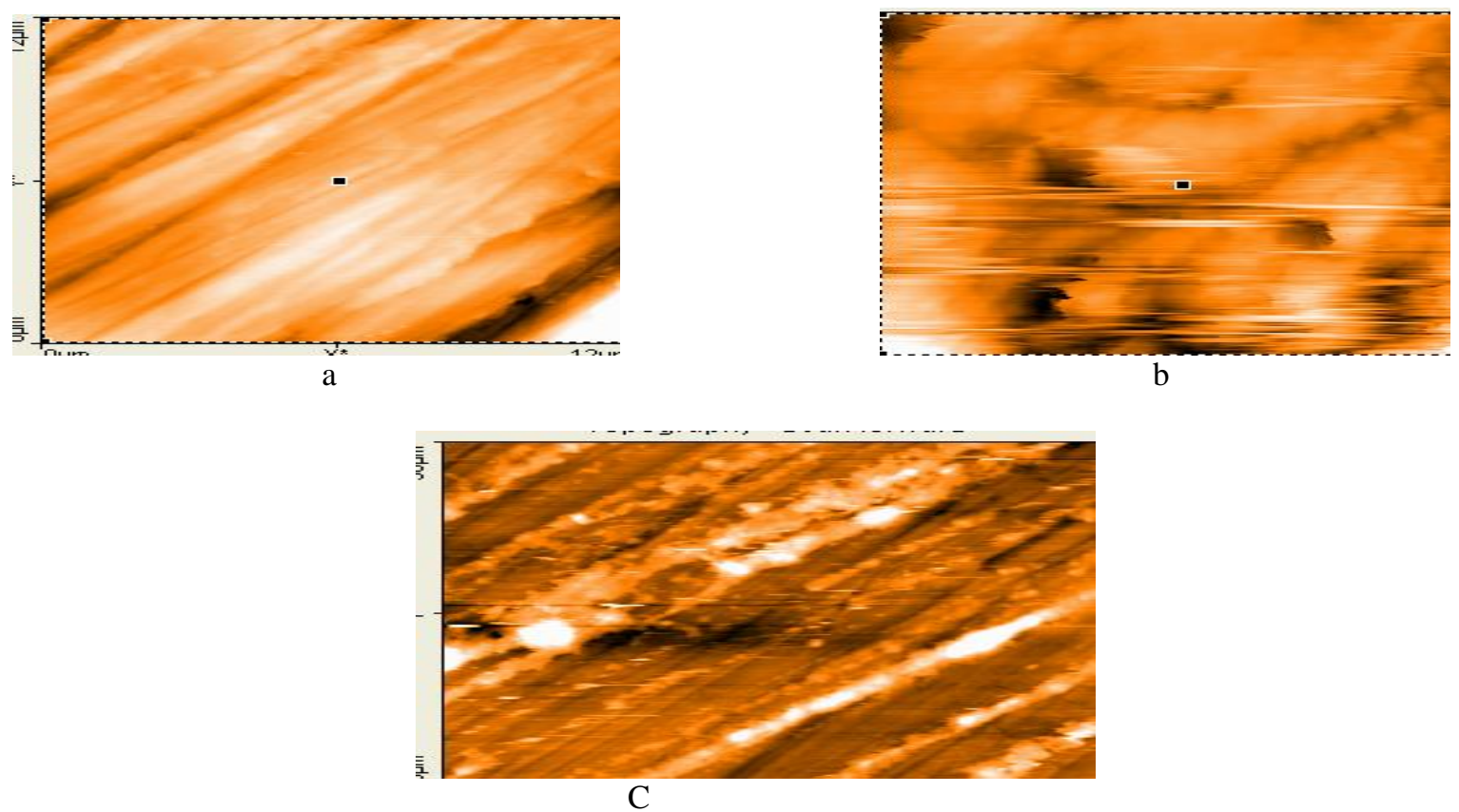

Fig. 11 Surface Characterization by AFM for mild steel in $1 \mathrm{M} \mathrm{HCl}$ a) Polished surface b) in the absence of inhibitor $\mathrm{c}$ ) in the presence of TDAB 